\title{
Decreased endothelium-dependent pulmonary vasodilator effect of calcitonin gene-related peptide in hypoxic rats contrasts with increased binding sites
}

\author{
M.M. Mannan*, D.R. Springall*, C. Enard**, A. Moradoghli-Haftvani*, \\ S. Eddahibi**, S. Adnot**, J.M. Polak*
}

Decreased endothelium-dependent pulmonary vasodilator effect of calcitonin generelated peptide in hypoxic rats contrasts with increased binding sites. M.M. Mannan, D.R. Springall, C. Enard, A. Moradoghli-Haftvani, S. Eddahibi, S. Adnot, J.M. Polak. CERS Journals Ltd 1995.

ABSTRACT: Levels of calcitonin gene-related peptide (CGRP), a vasodilator peptide present in nerves and airway endocrine cells of the rat respiratory tract, are increased in hypoxic lung and decreased in plasma, suggesting impaired CGRP release. We wanted to determine whether there was an adaptive functional response to reduced CGRP levels in hypoxia. Density of binding sites for CGRP were compared with its vascular actions following hypoxia, and with binding following administration of the sensory neurotoxin capsaicin to deplete neural CGRP.

Autoradiography of lung sections incubated with ${ }^{125}$ I-labelled CGRP and other vasoactive peptides was used to quantify their binding sites, in male Wistar rats exposed to periods of hypoxia (inspiratory oxygen fraction $\left(F \mathrm{I}, \mathrm{O}_{2}\right)=0.1$ ) ranging 0-10 days $(n=5$ each), in controls, and in rats treated neonatally with capsaicin. Relaxation to CGRP was compared in pulmonary artery of control and hypoxic rats.

CGRP binding was seen in the vascular endothelium and was significantly elevated after 5 days of hypoxia (mean \pm SEM: control $4.6 \pm 0.4$ versus hypoxic $\left.16.6 \pm 2.4 \mathrm{amol} \cdot \mathrm{mm}^{-2}\right)$. CGRP-induced $\left(5 \times 10^{-7} \mathrm{M}\right)$ relaxation of pulmonary artery was reduced, compared with controls, following 8 and 21 days of hypoxia (mean \pm SEM) percentage of relaxation to phenylephrine: $78 \pm 3,36 \pm 5$ and $32 \pm 3$, respectively) and was abolished by removal of endothelium. Capsaicin treatment also significantly elevated vascular CGRP binding. Atrial natriuretic peptide (ANP) binding levels were decreased in smooth muscle of all blood vessels after 7 days of hypoxia, but endothe Iin-1 (ET-1) and vasoactive intestinal peptide (VIP) binding was unchanged.

We conclude that the vasodilator effects of CGRP are endothelium-dependent and, whilst they are reduced in hypoxic lung, this is not due to reduction in receptors, thereby implicating alterations in the nitric oxide guanylyl cyclase system. Furthermore, adaptive responses in some peptide binding sites occur in hypoxia, which may be due to changes in endogenous peptide levels.
Eur Respir J., 1995, 8, 2029-2037.

*Dept of Histochemistry, Royal Postgraduate Medical School, Hammersmith Hospital, London, UK. **Département de Physiologie et INSERM U 296, CHU Henri Mondor, Créteil, France.

Correspondence: D.R. Springall

DeptofHistochemistry

RoyalPostgraduateMedicalSchool

Hammersmith Hospital

DuCaneRoad

LondonW120NN

UK

Keywords: Atrial natriuretic factor binding sites

calcitonin gene-related peptide

capsaicin

lung

nitric oxide

\section{Received: June 281993}

Accepted after revision August 151995
Pulmonary vascular tone is regulated by many vasoactive mediators produced either locally in endothelium, airway epithelium, vascular smooth muscle or nerves, or systemically via the blood. The main effect of alveolar hypoxia is pulmonary hypertension, which is modulated by many counteracting mediators. Amongst the possible candidates is calcitonin gene-related peptide (CGRP) [1], a potent vasodilator that is also present in the sensory innervation and endocrine cells of the rat respiratory tract [1-3], which is known to be involved in regulating pulmonary vascular tone $[2,4]$.

In previous studies, hypoxia has been shown to cause an increase in whole lung CGRP concentrations [5], particularly in the pulmonary endocrine cells $[6,7]$, and decreased plasma levels of the peptide in rats [5]. Release of endogenous CGRP may be of importance in maintaing pulmonary equilibrium, and impaired release may, thus, be relevant to the pulmonary hypertension that is a consequence of hypoxia.

Peptides elicit their effect by interacting with specific receptors on the target cell, which in turn will activate various intracellular pathways that lead to a biological response. These receptors can be identified partly by ligand binding studies and localized quantitatively by using tissue sections for the binding. CGRP binding sites are of two types, termed CGRP1 and CGRP2 $[8,9]$.

We hypothesized that changes in the amount of CGRP released will be reflected by an adaptive response shown by changes in its binding sites and, thus, its physiological effects, and have directed our study to investigate the 
response to hypoxia of CGRP binding site density and physiological effects. In addition, we have compared the binding results with those in animals treated systemically with the sensory neurotoxin, capsaicin, which depletes CGRP-immunoreactive fibres, including those in the lung [1], thereby reducing CGRP release. We have also examined the effects of hypoxia on the binding sites for other pulmonary vasoactive peptides, such as endothelin [10], atrial natriuretic peptide (ANP) [11] and vasoactive intestinal polypeptide (VIP) [12].

\section{Materials and methods}

\section{Reagents and drugs}

Anatomical studies. Hyperfilm and $\left(2-\left[{ }^{125} \mathrm{I}\right]\right.$ iodohistidy $1^{10}$ ) human CGRP (hCGRP), (3-[25I] iodotyrosyl) porcine ET-1, (3-[125I] iodotyrosyl) rat $\alpha-\mathrm{ANP}_{1-28}$, (3$\left.{ }^{125} \mathrm{I}\right]$ iodotyrosyl) VIP (all of specific activity 2,000 $\mathrm{Ci} \cdot \mathrm{mmol}^{-1}$ ) and ${ }^{125} \mathrm{I}$ radioactive standards were obtained from Amersham (Bucks, UK). Unlabelled hCGRP, $\alpha$ hCGRP $_{8-37}$, [Cys(ACM) $\left.{ }^{2,7}\right]$ hCGRP, endothelin-1 (ET- 1), sarafotoxin-6c and ANP were obtained from Peninsula Laboratories Europe Ltd; unlabelled VIP and bovine serum albumin (fraction V, protease-free) from Sigma Chemical Co. Ltd (Dorset, UK); sodium pentobarbitone from RMB Animal Health Ltd (Dagenham, Essex, UK); Tissue-Tek ${ }^{\circledR}$ optimal cutting temperature (OCT) embedding medium from Miles Ltd (Slough, Bucks, UK); dichlorofluoromethane (Arcton 12) from ICI (Cheshire, UK); D-19 developer from Kodak Ltd, (Hemel Hempstead, UK); Amfix from Champion Photochemistry (Brentwood, Essex, UK); and K5 emulsion from Ilford Scientific Products (Ilford Ltd, Mobberley, Cheshire, UK). All other reagents were obtained from BDH (Poole, Dorset, UK).

Physiological studies. Meclofenamate purchased from Substantia (Orléans, France) was diluted in saline, rat $\alpha$-CGRP (Sigma) was dissolved in distilled water to form a $10^{-2} \mathrm{M}$ stock solution, divided into aliquots and stored at $-20^{\circ} \mathrm{C}$. All other chemicals, L-phenylephrine hydrochloride, acetylcholine chloride, $\mathrm{L}-\mathrm{N}^{\mathrm{G}}$-nitroarginine methyl ester (L-NAME) and methylene blue (MB) were obtained from Sigma and prepared daily in saline solution.

\section{Hypoxia exposure}

Adult male Wistar rats (200-230 g) were divided into nine groups ( $\mathrm{n}=5$ each). Eight were exposed to hypoxia for $4,8,16,24 \mathrm{~h}$ and $3,5,7$ and 10 days ( $\mathrm{n}=5$ each). The remaining group was kept in the same room exposed to the same light and dark cycle, breathing room air (normoxic controls). To establish an hypoxic environment, a flexible hypoxic chamber was initially flushed with nitrogen until the oxygen tension fell to $10 \%$. The environment was routinely monitored with a polarographic oxygen analyser (with preset upper and lower limits of 11 and $9 \%$ ), which regulated the oxygen tension within the chamber via a solenoid valve controlling the nitrogen supply. If the oxygen tension rose above $11 \%$, the solenoid was activated, flushing the chamber with nitrogen to re-establish the environment within the specified limits. The $\mathrm{CO}_{2}$ levels were monitored using a capnometer with a rapid response time (Hewlett Packard 47210A, Massachusetts, USA) and did not rise above $0.4 \%$. The fractional gas concentrations were maintained within the specified limits at all times, except when the chamber was opened daily for no more than $30 \mathrm{~min}$ to allow cleaning and replenishment of food and water. Carbon dioxide and excess humidity were removed by means of filters containing soda lime and silica gel. The chamber was cooled by refrigerator units to $2-3^{\circ} \mathrm{C}$ above ambient. Pellet diet and tap water were given ad libitum to all animals, which were housed three to a cage.

In separate experiments to study physiological vascular responses to CGRP, male Wistar rats weighing $250-300 \mathrm{~g}$ were randomly divided into three groups. Two groups of rats were exposed to chronic hypoxia for 8 days and 3 weeks, respectively, and one group maintained in room air (control normoxic group). AU hypoxic and normoxic rats were kept in the same room, with the same light-dark cycle. Rat chow and tap water were provided ad libitum. Rats were exposed to hypoxia inspiratory oxygen fraction $\left(F \mathrm{I}, \mathrm{O}_{2}\right) 10 \%$ in a $500 \mathrm{~L}$ ventilated chamber (Flufrance apparatus, Cachan, France) as described previously [13]. Hypoxic rats were studied within $1 \mathrm{~h}$ of removal from the chamber.

\section{Capsaicin treatment}

Male Wistar rats (8 days old) were treated with capsaicin (8-methyl-N-vanillyl 6-nonanamide; Fluka AG) in order to cause a permanent depletion of primary afferent neurones and their peptide content. The rats received a single intraperitoneal injection $\left(50 \mathrm{mg} \cdot \mathrm{kg}^{-1}\right)$ of capsaicin under light anaesthesia. Capsaicin was prepared in a vehicle solution $\left(10 \mathrm{mg} \cdot \mathrm{mL}^{-1}\right)$ containing $10 \%(\mathrm{v} / \mathrm{v})$ ethanol, $10 \%(\mathrm{v} / \mathrm{v})$ Tween 80 , and $80 \% \mathrm{v} / \mathrm{v}$ isotonic saline. Control animals were injected with vehicle only. The pups were weaned and sexed at age 21 days, and tissues were collected 21 days after the injections.

\section{Tissue collection}

Animals were killed by an overdose of sodium pentobarbitone $\left(200 \mathrm{mg} \cdot \mathrm{mL}^{-1}\right)$ and the thorax was opened. Lungs were distended via the trachea with a mixture $(1: 1 \mathrm{v} / \mathrm{v})$ of $0.01 \mathrm{M}$ phosphate-buffered saline (PBS), $\mathrm{pH}$ 7.4, and OCT embedding medium. The trachea was clamped and a slice of lung was cut at the hilar level of the left lobe, mounted in OCT on a cork tile, snap frozen in melting dichlorodifluoromethane and stored at $-70^{\circ} \mathrm{C}$. Frozen sections (10 $\mu \mathrm{m}$ thick) were taken up on gelatinecoated glass slides.

Tissues from capsaicin-treated and control animals were collected for immunofluorescence staining as well as for ligand binding studies. Lungs for immunostaining 
were distended via the trachea with Zamboni's solution, removed from the thorax and immersed for $4 \mathrm{~h}$ in the same fixative. Tissues were sliced, washed with a $15 \%$ solution of sucrose in PBS, and then frozen and sectioned as above.

\section{In vitro ligand binding}

The binding characteristics were initially determined from experiments with various buffers and measurement of association, saturation and dissociation of the different ligands. The optimal incubation conditions were, thus, established for identifying CGRP, ET-1, VIP and ANP binding sites in the rat lung in order to maximize the ratio of specific to nonspecific binding. Nonspecific binding was defined as the amount of ${ }^{125} \mathrm{I}$-labelled ligand bound in the presence of excess $\left(10^{-6} \mathrm{M}\right)$ unlabelled homologous peptide. The incubation conditions and buffers finally used were selected as those found to give specific binding greater than $90 \%$ of the total binding, and are shown in table 1 . Sections were washed in a preincubation buffer for $15 \mathrm{~min}$ at room temperature to remove any bound endogenous ligand before applying the ${ }^{125} \mathrm{I}-$ labelled ligand.

Binding specificity was further established by coincubating sections with excess $\left(10^{-6} \mathrm{M}\right)$ unrelated peptides, e.g. ${ }^{125} \mathrm{I}-\mathrm{hCGRP}$ with ET-1, VIP and ANP, etc. Two kinds of CGRP receptor subtypes have been distinguished in rat tissue, CGRPl and CGRP2 [8, 9], and binding site heterogeneity has been demonstrated on the basis of differential antagonist and agonist potencies of the C-terminal hCGRP sequences and linear analogues. We therefore also investigated the effect of competitive inhibition of the C-terminal antagonist $\alpha$-hCGRP - $_{8-37}$ and the linear analogue [acetamidomethyl-Cys ${ }^{2,7}$ ]hCGRP ([Cys (ACM $\left.)^{2,7}\right]$ hCGRP). In addition, the effect of increasing concentrations $\left(10^{-9}\right.$ to $\left.10^{-5} \mathrm{M}\right)$ of the nonhydrolysable guanosine triphosphate analogue, guanosine 5'-O-(3-thiot-riphosphate) (GTP- $\gamma-\mathrm{S})$ on the binding affinity was investigated. The effects of the ET agonist sarafotoxin 6c (S6c) and antagonist BQ-123 (a gift from Banyu Pharmaceutical Co. Ltd, Tsukuba, Japan) on ${ }^{125}$ I-ET-1 binding was similarly investigated.

At the end of the incubation period (see table 1), sections were rinsed twice for $5 \mathrm{~min}$ in ice-cold Tris/ $\mathrm{HCl}$ or phosphate buffer and deionized water before being dried under a stream of cold air.

\section{Macro autoradiography}

Slides were placed in autoradiography cassettes and exposed to radiation-sensitive film (Hyperfilm $\beta \max$ ) together with ${ }^{125} \mathrm{I}$ radioactivity standard sections at $4{ }^{\circ} \mathrm{C}$ for 5 days for CGRP, 1 day for ET-1, 6 days for VIP and 2 days for ANP. The films were developed in Kodak D-19 developer, fixed with a high speed fixer (Amfix), rinsed and dried. The resulting autoradiograms were analysed and quantified using a Kontron IBAS 2000 (Kontron Elektronik, Watford, Herts, UK) image analyser.

Optical densities of the labelling in the smooth muscle both of airways and blood vessels were measured as grey levels. Using a calibration curve constructed from the grey levels of the ${ }^{125} \mathrm{I}$ standards co-exposed with each film, grey level values were converted to attomoles (amol) of ligand bound per unit area of tissue. Specific binding was obtained by subtracting nonspecific binding from the total binding measured in the same tissue areas. The binding experiments were performed five times; thus, each animal in each hypoxic group had measurements made on five sections. Fifty areas were measured each in blood vessels and airways per section in each experiment from which means and SEMS were derived.

Data were, thus, calculated for binding sites in blood vessels and airways for each of the different periods of hypoxia. Differences in binding to the various tissue structures between the different periods of hypoxia were analysed using one-way analysis of variance (ANOVA) in the statistical package INSTAT (GraphPAD Software, San Diego, USA). Significance was assumed if $\mathrm{p}$ was less than 0.05 .

\section{Micro autoradiography}

After exposure to film, sections were postfixed by immersion in Bouin's solution for $1 \mathrm{~h}$ at room temperature, rinsed twice in PBS for 5 min and then dried in air before being coated with liquid emulsion (Ilford K5 nuclear emulsion) at $42^{\circ} \mathrm{C}$. Coated sections were air dried

Table 1. - Conditions and reagents used for in vitro ligand binding

\begin{tabular}{|c|c|c|c|}
\hline Peptide & Preincubation buffer ( $15 \mathrm{~min})$ & Ligand (concentration) & $\begin{array}{l}\text { Incubation time } \\
\text { min }\end{array}$ \\
\hline CGRP & $\begin{array}{l}\text { Tris/HCl } 50 \mathrm{mM}(\mathrm{pH} 7.4) \\
5 \mathrm{mM} \mathrm{MgCl}, 50 \mathrm{mg} \cdot \mathrm{L}^{-1} \text { bacitracin }\end{array}$ & ${ }^{125}$ I-CGRP (0.5 mM) & 90 \\
\hline ET-1 & $\begin{array}{l}\text { Tris/ } \mathrm{HCl} 50 \mathrm{mM}(\mathrm{pH} 7.4) \\
\mathrm{MgCl}_{2}, 40 \mathrm{mg} \cdot \mathrm{L}^{-1} \text { bacitracin }\end{array}$ & 125I-ET-1 $(0.3 \mathrm{nM})$ & 120 \\
\hline VIP & $\begin{array}{l}\text { Tris/ } / \mathrm{HCl} 50 \mathrm{mM}(\mathrm{pH} 7.4) \\
\mathrm{MgCl}_{2}, 40 \mathrm{mg} \cdot \mathrm{L}^{-1} \text { bacitracin }\end{array}$ & ${ }^{125}$ I-VIP $(0.4 \mathrm{nM})$ & 120 \\
\hline ANP & $\begin{array}{l}\text { Phosphate }(30 \mathrm{mM})(\mathrm{pH} 7.4) \\
120 \mathrm{mM} \mathrm{NaCl}, 40 \mathrm{mg} \cdot \mathrm{L}^{-1} \text { bacitracin }\end{array}$ & 125I-ANP (0.5 nM) & 30 \\
\hline
\end{tabular}

CGRP: calcitonin gene-related peptide; ET-1: endothelin-1; VIP: vasoactive intestinal peptide; ANP: atrial natriuretic peptide. 
in a dark room for $2 \mathrm{~h}$ and left to expose in a light-tight chamber containing silica gel at $4^{\circ} \mathrm{C}$ for 10 days for CGRP, 2 days for ET-1, and 12 days for VIP and ANP. The image was then developed in Kodak D-19 developer $\left(4 \mathrm{~min}, 18^{\circ} \mathrm{C}\right)$ and fixed with Amfix. The sections were counterstained with haematoxylin and eosin and mounted in synthetic medium (Pertex, Cellpath plc., Hemel Hempstead, UK). Silver grains were visualized using brightfield microscopy to show the localization of CGRP, ET-1, VIP and ANP binding sites.

\section{Immunofluorescence staining}

To ascertain that sensory nerve depletion had occurred after capsaicin treatment a modified indirect staining technique [1] was used with antisera to CGRP, which is sensory in origin, and to the parasympathetic peptide VIP as a control. Briefly, sections were pretreated for 30-60 min in PBS containing 0.2\% Triton X-100, and counterstained with Pontamine sky-blue for 30 min prior to the application of the first layer antiserum, followed by an overnight incubation at $4^{\circ} \mathrm{C}$. The primary antiserum was washed off and then reapplied for $4 \mathrm{~h}$ at room temperature, after which the sections were washed and incubated with fluorescein-isothiocyanate(FTTC)-labelled goat anti-rabbit immunoglobulin $\mathrm{G}(\mathrm{IgG})$ (1:100 dilution, Tago Inc., Burlingame, USA) for $1 \mathrm{~h}$ at room temperature. After PBS washes, the sections were mounted in glycerol:PBS $(1: 1 \mathrm{v} / \mathrm{v})$. The preparations were examined using a microscope equipped with epi-illumination for fluorescence staining (model AH-2, Olympus, UK).

\section{Isolated vascular rings}

Rats were anaesthetized with pentobarbital $100 \mathrm{mg} \cdot \mathrm{kg}^{-1}$ i.p. The chest was opened, and heparin sulphate (100 IU) was injected into the right ventricle. The heart and lungs were removed en bloc. The extrapulmonary left and right branches of the pulmonary artery were isolated and placed in cold Earle's balanced salt solution of the following composition (in $\mathrm{mM}$ ): 5.5 glucose; $0.83 \mathrm{MgSO}_{4} ; 1.8 \mathrm{CaCl}_{2} ; 116 \mathrm{NaCl} ; 1.04 \mathrm{NaH}_{2} \mathrm{PO}_{4} ; 19$ $\mathrm{NaHCO}_{3} ; 4.7 \mathrm{KCl}$; with phenol red $\mathrm{Na}\left(0.11 \mathrm{~g} \cdot \mathrm{L}^{-1}\right)$ included as a $\mathrm{pH}$ indicator and meclofenamate $(3.2 \mu \mathrm{M})$ added to inhibit prostglandin synthesis. After gentle removal of surrounding adventitia, rings $2-3 \mathrm{~mm}$ in length were cut. In some preparations, care was taken to avoid endothelium damage; in others, the endothelium was removed mechanically by inserting a nylon thread into the lumen and gently rubbing the endothelium. Vessel rings, were mounted horizontally between two steel stirrups in organ chambers containing $10 \mathrm{ml}$ of the Earle's salt solution bubbled with $20 \% \mathrm{O}_{2}$ and $5 \% \mathrm{CO}_{2}\left(37^{\circ} \mathrm{C}, \mathrm{pH} 7.4\right)$. At the start of the experiment, resting passive force was adjusted to $0.75 \mathrm{~g}$. This value was determined to be the optimum resting force for similar sized vessels in previous experiments. This passive force was defined as zero, and all subsequent measurements are presented as active force generated above the baseline.
After a resting period (60 min) during which tension was readjusted and the bath flushed several times, rings were exposed to $\mathrm{KCl}(50 \mathrm{mM})$. Following maximal contraction, the organ chamber was rinsed. The rings were then contracted with a submaximal concentration of phenylephrine $\left(10^{-6} \mathrm{M}\right)$ and checked for intact endothelium by confirming at least $80 \%$ relaxation to acetylcholine $\left(10^{-6} \mathrm{M}\right)$. Tissues showing less than this level of relaxation were discarded as having partially damaged endothelium. The rings were then rinsed three times with fresh buffer and precontracted again; after stabilization of the contraction, rat $\alpha$-CGRP was added in a cumulative fashion. Following administration of the highest concentration of relaxant, rings were rinsed three times with fresh buffer and allowed to return to baseline force.

Vasodilator responses to rat a-calcitonin gene-related $(C G R P)$ in pulmonary arteries

Vasodilator responses to CGRP $\left(10^{-10}\right.$ to $\left.10^{-6} \mathrm{M}\right)$ were tested in pulmonary arteries from normoxic, 8 day and 3 week hypoxic rats. In pulmonary arteries obtained from control normoxic rats, the response to CGRP was also studied in endothelium-denuded preparations as well as in the presence of L-NAME $10^{-4} \mathrm{M}$, an inhibitor of NO synthase, or MB $10^{-4} \mathrm{M}$, an inhibitor of soluble guanylyl cyclase. In these experiments, the inhibitor was added to the organ bath $15 \mathrm{~min}$ before establishing the dose-response curve to CGRP.

\section{Statistical analysis}

Relaxation was expressed as the percentage of contraction to phenylephrine $\left(10^{-6} \mathrm{M}\right)$. Results are given as mean \pm SEM. Two-way ANOVA with repeated measurements were performed. Vasodilation to rat $\alpha$-CGRP was compared in the two different hypoxic groups and in the normoxic group, testing for group effect, dose of the vasodilator agent and interaction between group and dose. Because interaction was significant, nonparametric Kruskals-Wallis ANOVA and Mann-Whitney nonparametric tests were used to compare groups at each dose of the vasodilator agent. Similarly, in the normoxic group, the effects of various pretreatments on vasodilatation to rat a-CGRP were compared by testing pretreatment effect, dose effect and interaction of dose and pretreatment. Differences were considered significant at a p-value less than 0.05 .

\section{Results}

Binding sites autoradiography revealed specific ${ }^{125} \mathrm{I}-$ CGRP, ET-1, VIP and ANP binding as silver grains over discrete structures in rat lung. Adjacent sections incubated with ${ }^{125}$ I-labelled peptide in the presence of excess $\left(10^{-6}\right.$ M) unlabelled peptide had silver grains that were fewer in number and did not conform to the pattern of the underlying tissue (fig. 1). 

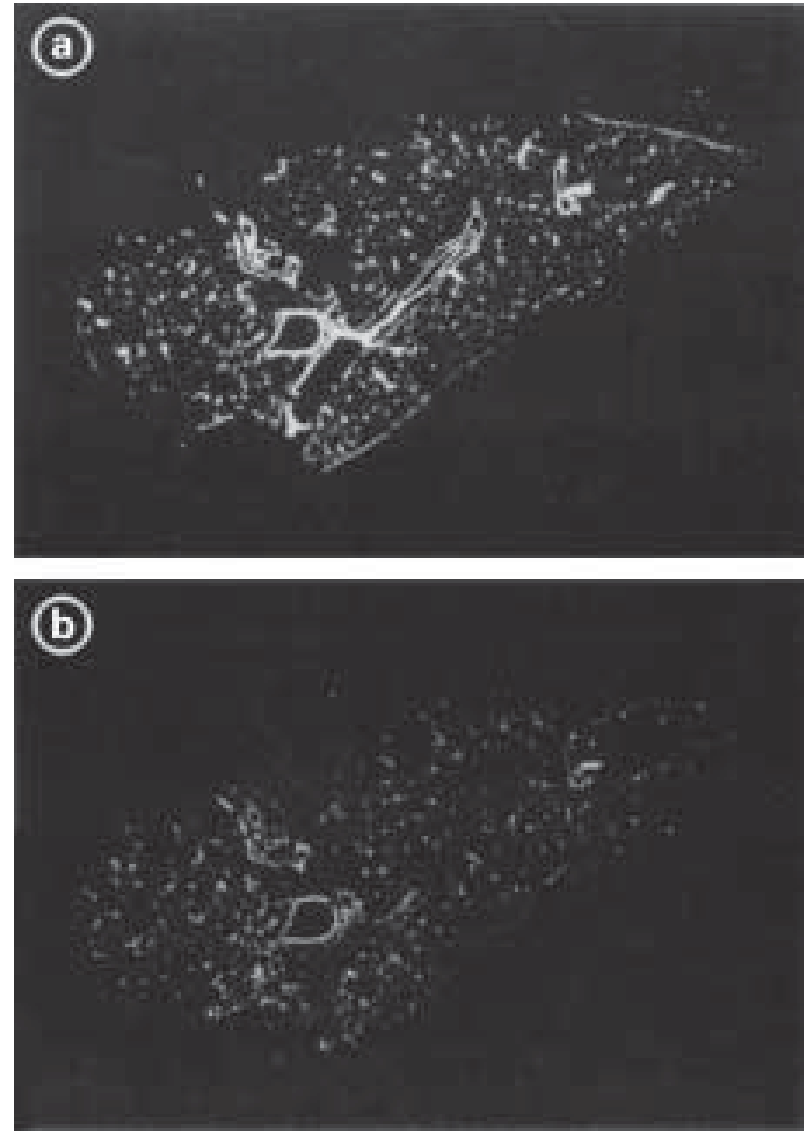

Fig. 1. - Autoradiogram showing localization of: a) ${ }^{125}$ I-hCGRP binding sites in hypoxic rat lung; and b) serial section inhibited in the presence of excess $\left(10^{-6} \mathrm{M}\right)$ unlabelled peptide. hCRGP: human calcitonin gene-related peptide.

In emulsion-dipped sections, CGRP binding was localized mainly to the endothelium and was seen in all pulmonary blood vessels (fig. 2a and b). No labelling was observed in the airways. ET-1, VIP and ANP binding was dense and of homogenous distribution in smooth muscle both of airways and blood vessels (fig. $2 \mathrm{c}$ and d).

Competition studies indicated that binding for CGRP was saturable and could be dissociated (fig. 3). It was not inhibited by unrelated peptides. Competitive inhibition studies indicated that there were differences in the potency of the different peptide sequences for ${ }^{125} \mathrm{I}$-hCGRP binding sites, the order of potency being hCGRP $>\alpha$ hCGRP $_{8-37}>\left[\mathrm{Cys}(\mathrm{ACM})^{2,7}\right]$ hCGRP (fig. 4a). The addition of GTP- $\gamma-\mathrm{S}$ caused a reduction in affinity of ${ }^{125} \mathrm{I}$-labelled CGRP in a concentration-dependent manner (fig. 4b).

\section{Effects of hypoxia on binding}

Total CGRP binding levels (fig. 5) were elevated in blood vessels of 5, 7 and 10 day hypoxic rat lung (control 4.6 \pm 0.4 vs 5 day hypoxic $16.6 \pm 2.4$, 7 day hypoxic $16.9 \pm 2.9$, and 10 day hypoxic $21.9 \pm 2.3 \mathrm{amol} \cdot \mathrm{mm}^{-2}$; $\mathrm{p}<0.005)$. No significant changes were observed in the airways after similar periods of hypoxia. The inhibition affinities for the C-terminal antagonist $\alpha$-hCGRP ${ }_{8-37}$ and

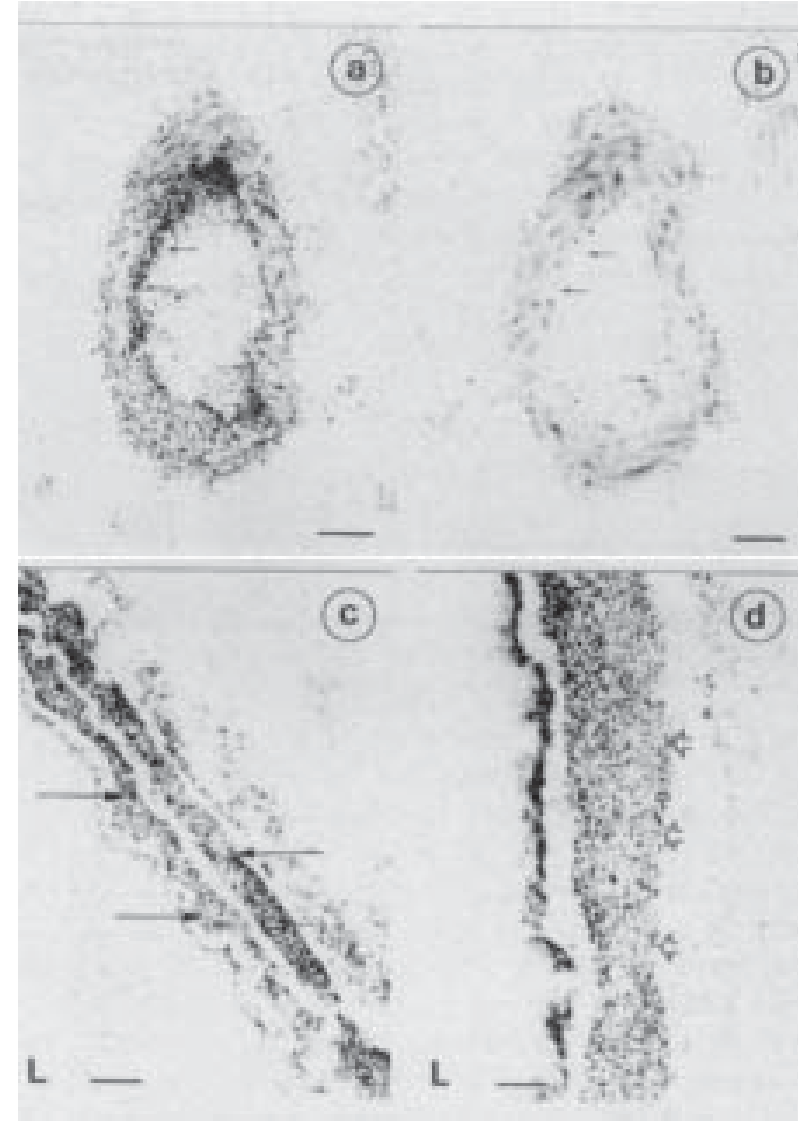

Fig. 2. - Photomicrograph showing localization of: a) ${ }^{125}$ I-hCGRP binding sites in rat lung on endothelium of pulmonary blood vessels (arrows) and b) displaced in the presence of excess unlabelled $\left(10^{-6} \mathrm{M}\right)$ peptide (arrows). (Internal scale bat=52 pm): c) ${ }^{125}$ I-ANP binding sites in smooth muscle of pulmonary blood vessels (arrows); and d) airways (open arrow heads) (L: lumen). (Internal scale bat=37 pm). Localization and distribution of ET-1 and VIP binding sites was similar to that seen with ANP. After capsaicin treatment. localization of binding sites for all the peptides was similar to that seen in sections from hypoxic animals. hCGRP: human calcitonin gene-related peptide; ANP: atria1 natriuretic peptide; ET-1: endothelin-t; VIP: vasoactive intestinal peptide.

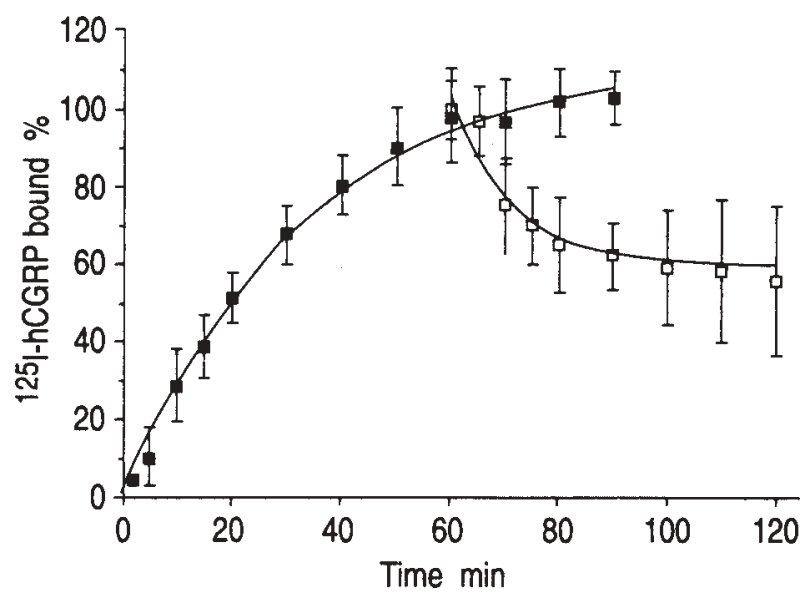

Fig. 3. - Association ( $\square$ ) and dissociation ( $\square)^{125}$ l-hCGRP binding in rat lung. Each point is the meanisw of 50 measurements. hCGRP: human calcitoningene-relafed peptide. 
a)

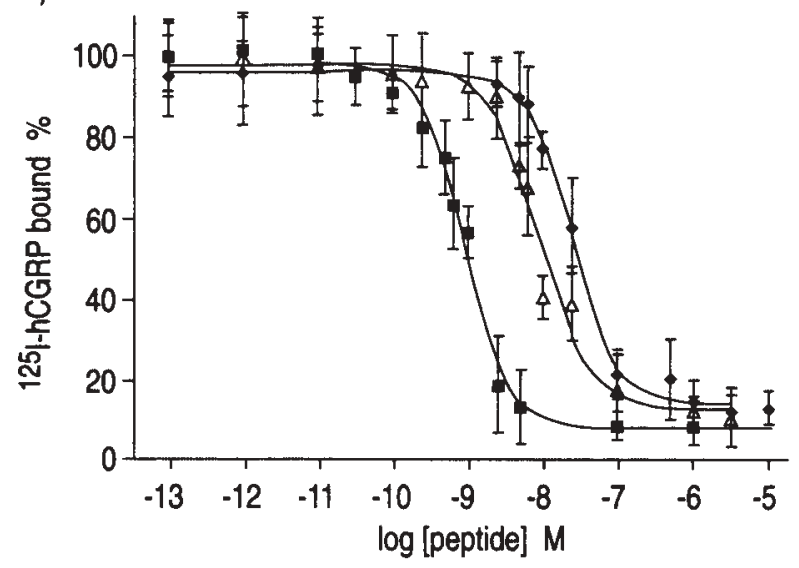

b)

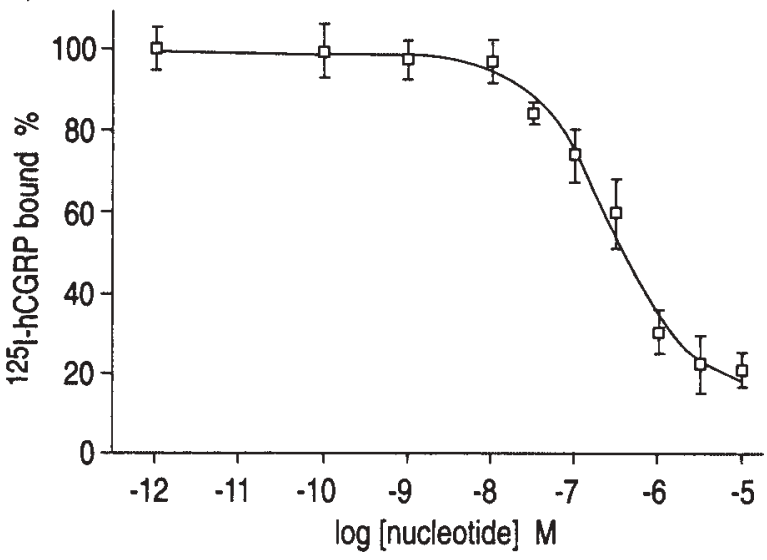

Fig. 4. - Competitive inhibition curves of specific ${ }^{125} \mathrm{I}$-hCGRF binding to rat lung in the presence of: a) increasing concentrations of hCGRF ( $\operatorname{hCGRP}_{8-37}(\Delta)$ and [Cys $\left.(\mathrm{ACM})^{2,7}\right] \mathrm{hCGRP}(\bullet)$; and b) GTP- $\gamma$-s. Each point is mean \pm sEM of 50 measurements. hCGRP; human calcitonin gene-related peptide; ACM: acetamidomethyl; GTP- $\gamma$-S: guanosine 5'-O-(3-thiotrio phosphate).
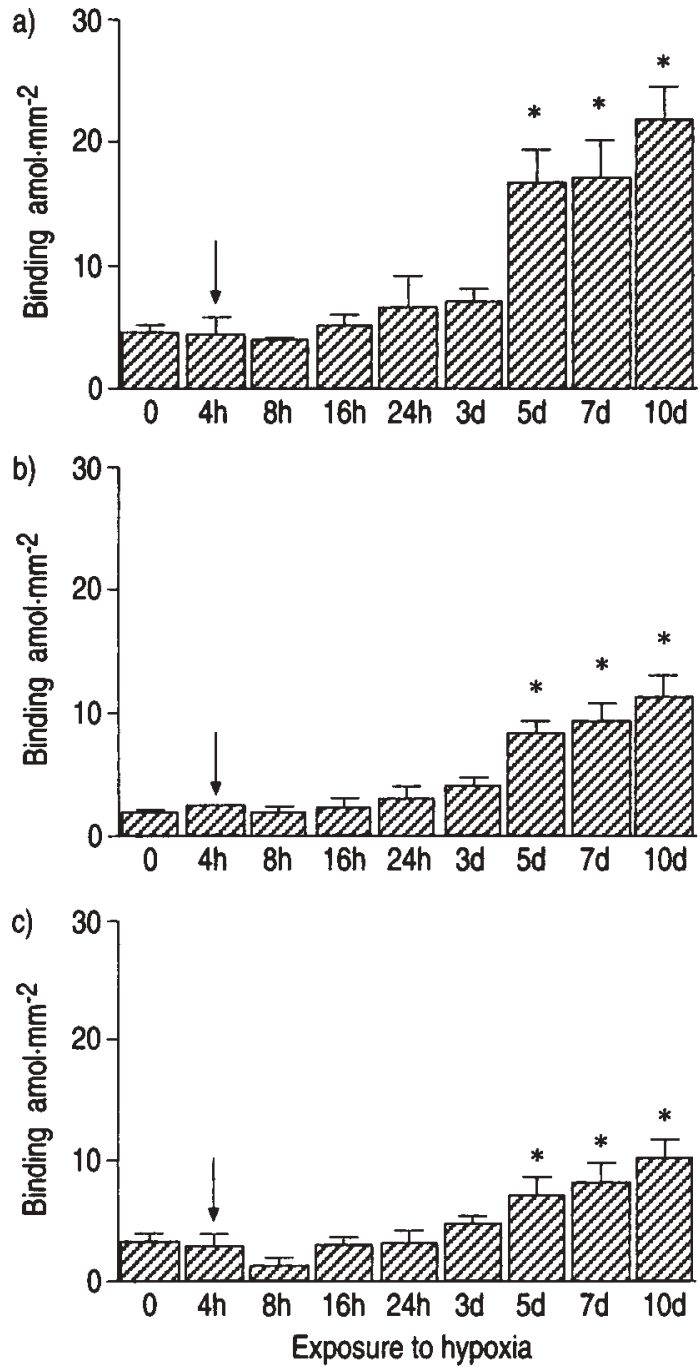

Fig. 5. - Histogram of results for the mean and SEM (error bars) of five animals showing: a) specific ${ }^{125}$ I-CGRP, b) CGRPI; and c) CGRP2 receptor binding levels in blood vessels of control and hypoxic rat lungs. The arrows indicate the time-points at which CGRP endocrine cell levels have been shown to change in hypoxia. *: $p<0.05$ compared to control (no exposure to hypoxia). CGRP; cakitonin generelated peptide; amokattomoles. linear analogue $\left[\mathrm{Cys}(\mathrm{ACM})^{2,7}\right]$ hCGRP were not significantly different in blood vessels over the same hypoxic periods, suggesting that two receptor subtypes may be present (figs. 4a and 5). Neither ET-1 nor VIP binding changed in airways or blood vessels in any hypoxic period when compared to controls. ET-l binding was reduced when competed by sarafotoxin 6c and BQ-123 both in blood vessels and airways (blood vessels: ET-1 191 $\pm 18.7, \mathrm{ET}_{\mathrm{A}}$ 88.4 \pm 5.3 , and $\mathrm{ET}_{\mathrm{B}} 92.6 \pm 8.2 \mathrm{amol} \cdot \mathrm{mm}^{-2}$; and airways:

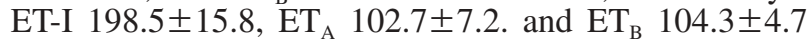
amol. $\mathrm{mm}^{-2}$, and the levels were not affected by hypoxia.

Total ANP binding (fig. 6) was decreased in blood vessels of 7 and 10 day hypoxic lung (control 46.2 \pm 5.2 vs 7 day hypoxic $33.5 \pm 2.0$, and 10 day hypoxic $28.5 \pm 2.4$ amol $\left.\cdot \mathrm{mm}^{-2}, \mathrm{p}<0.005\right)$. No changes in ANP binding were seen in the airways after similar periods of hypoxia.

\section{Eflects of capsaicin treatment on binding}

In control animals, strong CGRP-immunoreactivity was seen in many nerve fibres located around blood vessels, below and in airway epithelium, in airway

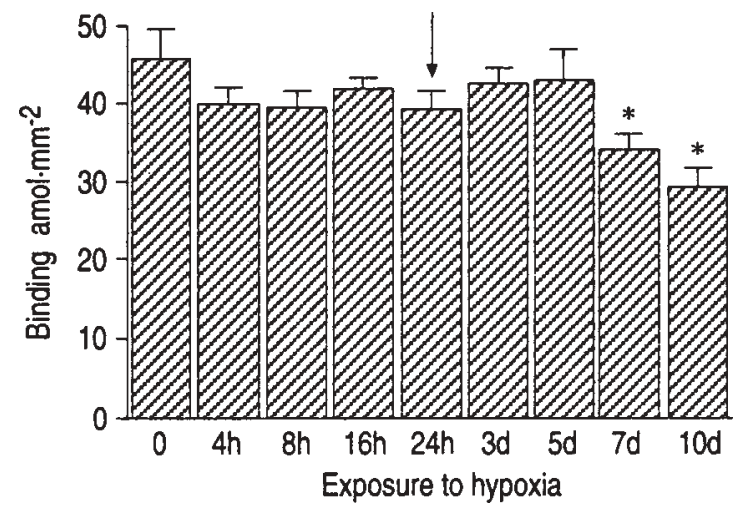

Fig. 6. - Histogram of results for the mean and SEM (error bars) of five animals showing ${ }^{125}$-ANP binding levels in blood vessels of control and hypoxic rat lung. The arrow indicates the time point at which ANP plasma levels have been shown to change in hypoxia. *: $\mathrm{p}<0.05$ compared to control (no exposure to hypoxia). ANP: atria1 natriuretic peptide; amok attomoles. 

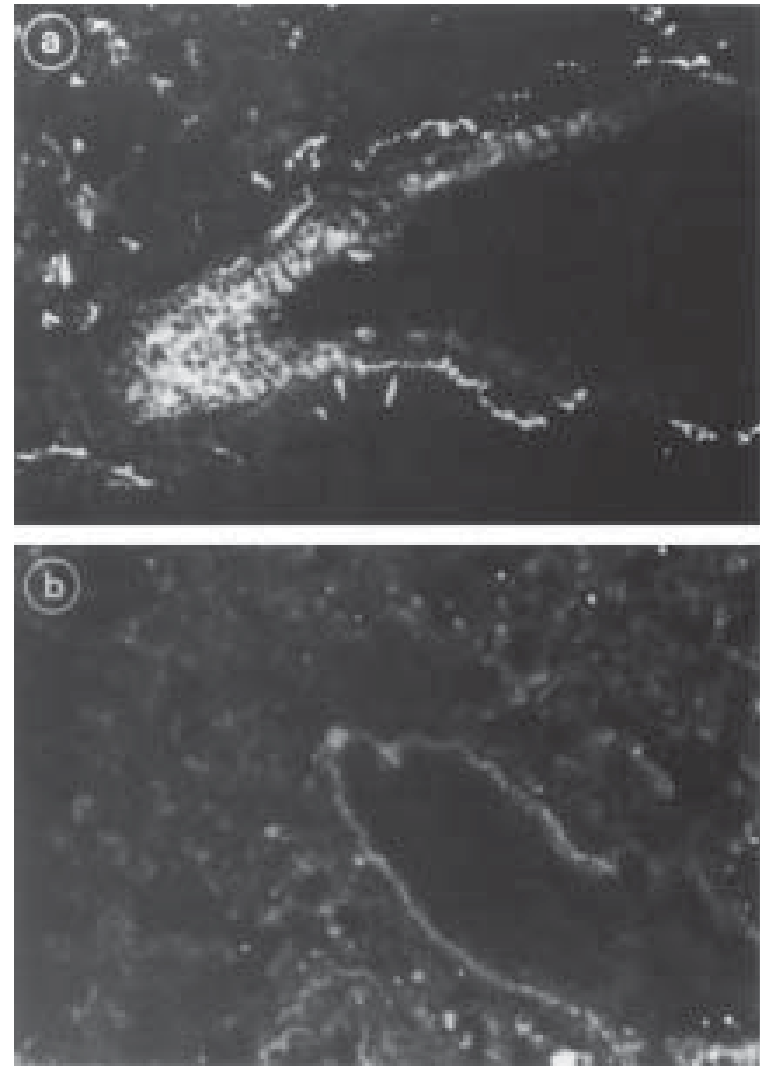

Fig. 7. - Immunofluorescence staining for calcitonin gene-related peptide (CGRP) in: a) control and; b) capsaicin-treated rat lung. CGRPimmunoreactive nerves in capsaicin-treated rat lung were absent.

smooth muscle and in epithelial endocrine cells. VIPimmunoreactive nerves were seen in airway smooth muscle, around bronchial vessels and the adventitia of pulmonary vessels. In capsaicin-treated animals, nerves immunoreactive for CGRP were greatly depleted (fig. 7), only a few weakly positive fibres being found. Immunoreactivity for VIP was the same in control and capsaicintreated animals.

Binding for ${ }^{125} \mathrm{I}-\mathrm{CGRP}$ was elevated in the endothelium of all pulmonary blood vessels in the capsaicintreated animals (control 46.27 $\pm 4.5 \mathrm{vs}$ capsaicin treatment $66.35 \pm 5.89 ; \mathrm{p}<0.005$ ) (fig. 8).

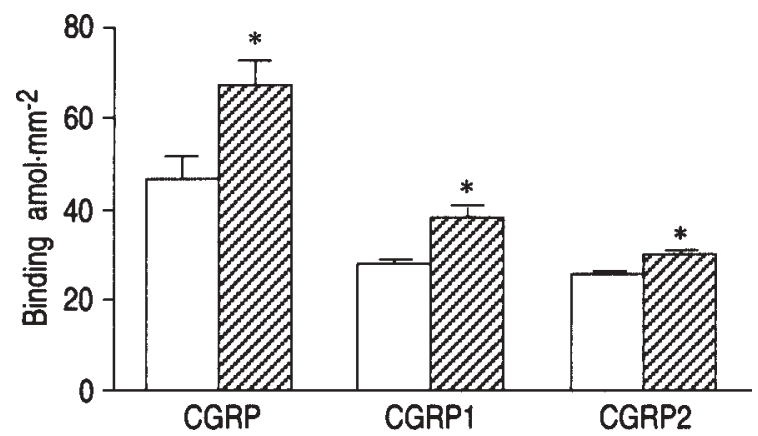

Fig. 8. - Histogram of results for the mean and SEM (error bars) of five animals showing ${ }^{125}$ I-CGRP binding levels in blood vessels of control and capsaicin-treated rat lung. $\square$ : control; $\nabla 7 \lambda$ : capsaicin *: $\mathrm{p}<0.05$ compared to corresponding control. For abbreviations see legend to figure 5 .
Endothelium-dependent relaxation in pulmonary arteries from normoxic and hypoxic rats

In pulmonary arteries from normoxic rats, CGRP $\left(10^{-10}\right.$ to $10^{-6} \mathrm{M}$ ) induced a concentration-dependent relaxation reaching $77 \pm 3 \%$ at $5 \times 10^{-7} \mathrm{M}$. The response was completely abolished in endothelium-denuded rings as well as in rings pretreated with L-NAME or MB (fig. 9).

In pulmonary arterial rings from rats exposed to 8 days or 3 weeks to hypoxia, the relaxant response to CGRP was reduced in comparison to the response obtained in normoxic control rats (fig. 10). The maximal relaxant response to CGRP was reduced to $36 \pm 5 \%(\mathrm{p}<0.001)$ and $32 \pm 3(\mathrm{p}<0.001)$ in 8 days and 3 weeks hypoxia rats, respectively, compared to $78 \pm 3 \%$ in pulmonary arteries from normoxic rats. No significant difference was noted between groups of hypoxic rats.

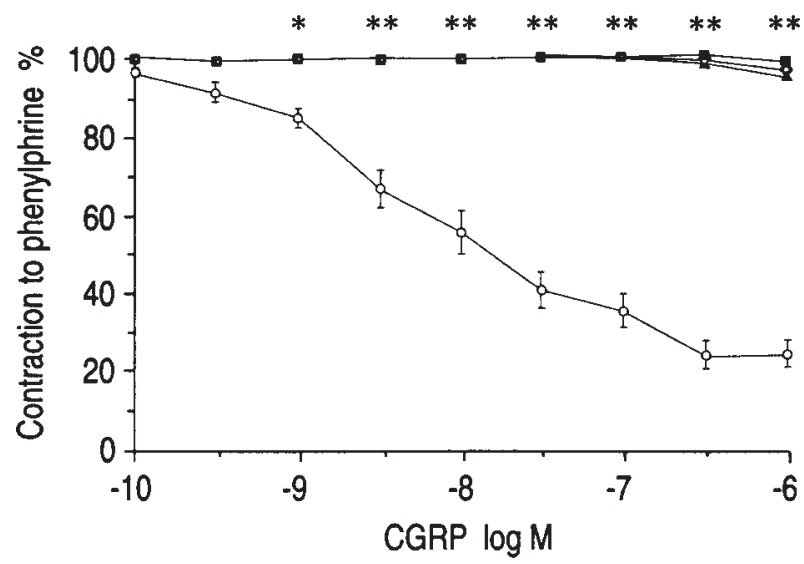

Fig. 9. - Relaxation of pulmonary arteries from normoxic rats induced by $\alpha$-calcitonin gene-related peptide $\left(\alpha\right.$-CGRP) $\left(10^{-10}\right.$ to $\left.10^{-6} \mathrm{M}\right)$ with endothelium (controls) and without endothelium. Responses to CGRP were also studied in control rings pretreated with $\mathrm{L}-\mathrm{N}^{\mathrm{G}}$-nitro arginine methyl ester (L-NAME) $\left(10^{-4} \mathrm{M}\right)$ or methylene blue $(\mathrm{MB})\left(10^{-4} \mathrm{M}\right)$ $(\mathrm{n}=6$ for each curve). $*$ : $\mathrm{p}<0.05 ; * *: \mathrm{p}<0.01$ in comparison with intact arteries. —०— : control; - ——: L-NAME; ———: MB; —०—: without endothelium.

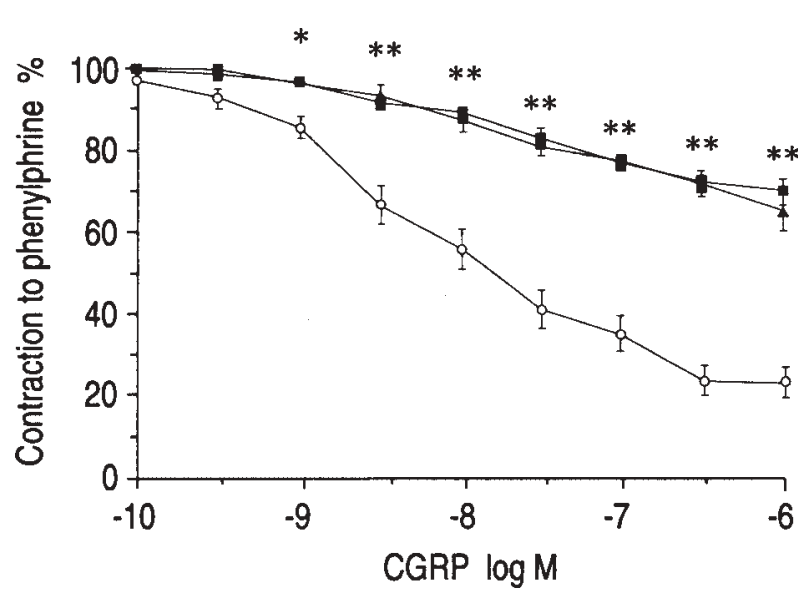

Fig. 10. - Relaxation to $\alpha$-calcitonin gene-related peptide ( $\alpha$-CGRP) in pulmonary arteries from rats exposed to 8 days or 3 weeks hypoxia compared to normoxic control rats. $*: \mathrm{p}<0.05$; $* *: \mathrm{p}<0.01$ in comparison with control normoxic rats. - - — : control; - - — : hypoxia (8 days); --: hypoxia (3 weeks). 


\section{Discussion}

In this study, we have demonstrated morphologically and functionally that CGRP acts in rat pulmonary vessels by an endothelium-dependent mechanism via nitric oxide, and that hypoxia causes an increase in the density of vascular CGRP binding sites but a decrease in the ability of the peptide to dilate pulmonary vessels.

CGRP binding to rat lung was rapid and saturable. Competition studies demonstrated that hCGRP inhibits ${ }^{125}$ I-hCGRP binding with a higher affinity than the antagonist $\alpha$-hCGRP ${ }_{8-37}$ and the analogue [Cys(ACM $)^{2,7}$ ] hCGRP, suggesting that CGRP binding sites may be more sensitive to $\alpha$-hCGRP ${ }_{8-37}$ than $\left[\mathrm{Cys}(\mathrm{ACM})^{2,7}\right]$ hCGRP. These results suggest that ${ }^{125} \mathrm{I}$-hCGRP binding sites may be sensitive to structural changes in the hCGRP molecule, in that removal or modification of the N-terminal caused a reduction in inhibitory potency, as seen with $\alpha$-hCGRP ${ }_{8-37}$ and $\left[\mathrm{Cys}(\mathrm{ACM})^{2,7}\right]$ hCGRP compared to hCGRP. Similar observations have been made previously in rat brain and cultured neonatal rat cardiac myocytes $[14,15]$. However, in membrane preparations of rat and guinea-pig tissues, $\alpha$-hCGRP ${ }_{8-37}$ has been shown to have a greater inhibitory potency relative to hCGRP for ${ }^{125} \mathrm{I}$-hCGRP binding sites [8], suggesting that there may be regional or species differences in the binding affinity of ${ }^{125}$ I-hCGRP binding sites.

The inhibition of ${ }^{125}$ I-hCGRP binding by GTP- $\gamma-\mathrm{S}$ suggests that ${ }^{125} \mathrm{I}$-hCGRP binding sites interact with a guanine nucleotide protein ( $\mathrm{G}$ protein) and involves a mechanism whereby a high affinity binding site and $\mathrm{G}$ protein are converted to a lower affinity unbound site [16]. Studies on rat cerebellum and myocardial cell membranes have shown that CGRP binding sites can occur in different affinity states [14, 15]. However, whilst the concentration-dependent inhibition of ${ }^{125} \mathrm{I}$ hCGRP binding by GTP- $\gamma-S$ suggests that high-affinity binding sites are present in the rat lung, the near complete dissociation of ${ }^{125} \mathrm{I}-\mathrm{hCGRP}$ by GTP- $\gamma-\mathrm{S}$ and incomplete dissociation with hCGRP further suggest that binding sites for CGRP in rat lung may also occur in other affinity states. The effect of GTP-)I-S and the lack of binding inhibition by unrelated peptides further emphasizes the binding specificity in rat lung. Our results, therefore, provide evidence that ${ }^{125} \mathrm{I}$-hCGRP binding sites are present in the rat lung and are regulated by guanine nucleotides, which is in agreement with similar behaviour seen with CGRP binding sites in other tissues $[14,15,17]$.

CGRP binding sites were located principally on vascular endothelium, which implies that the vascular effects of CGRP in the rat lung are endothelium-dependent, unlike humans, where the receptors are predominantly on the vascular smooth muscle [18]. This was confirmed by physiological studies showing that CGRP vasodilatation in pulmonary artery rings was abolished by removal of the endothelium and by pretreatment with L-NAME which blocks NO (endothelium derived relaxing factor) formation by inhibiting NO-synthase, or with methylene blue which inactivates soluble guanylyl cyclase, the effector of NO-induced smooth muscle relaxation. The results are consistent with those previously obtained in guinea-pig showing a role of NO in mediating nonadrenergic, noncholinergic pulmonary arterial relaxation [19]. Because impairment of endothelium-dependent pulmonary vasodilatation has previously been demonstrated during chronic hypoxia, the NO-mediated vasodilator response may also become altered during chronic hypoxic pulmonary hypertension [20, 21], which could then lead to increased synthesis of vasoconstrictors, such as endothelin [22]. Consistent with this hypothesis, we found that CGRP-induced relaxation was attenuated in pulmonary artery rings from hypoxic rats compared with normoxic animals. This suggests that during chronic hypoxia, counteracting vasodilator mechanisms, such as that represented by CGRP, may become impaired. However, during acute hypoxia, which is not associated with such alteration in NO-mediated pulmonary vasodilatation [23], CGRP may play an important role in modulating vascular tone. The pulmonary endocrine cells, found scattered in the airway epithelium, are a major source of CGRP in rat lung [1]. They are known to respond to changes in oxygen tension [6, 24, 25], and suggested to contain increased levels of CGRP [7] from $4 \mathrm{~h}$ after exposure of rats to hypoxia [26], which is reinforced by the finding of increased CGRP concentration in lung homogenates [5]. This higher level of CGRP could represent a suppression of its release, which is supported by decreased levels of CGRP in plasma [5], and the reversal of hypoxic pulmonary vascular remodelling by administration of CGRP [27]. Our finding of elevated CGRP binding sites in hypoxia supports the contention that hypoxia may lead to a suppression or reduction of pulmonary CGRP release, which in turn leads to an upregulation of CGRP receptors.

Elevation of binding levels in response to a reduction of peptide secretion seems to be a mechanism by which target cells maximize the use of the peptide available, maintaining normality by upregulating binding when the agonist is scarce [28] or when deficiencies occur in the effector system, such as was found in this study. In view of the vasodilator effects of CGRP in the lung [4], our results also suggest that the mechanisms by which the peptide modulates pulmonary changes in hypoxia are mediated by the regulation of binding sites in target cells. The increased levels of CGRP binding in the lungs of capsaicin-treated animals support our suggestion that elevation of CGRP binding levels is a concomitant response needed to counteract the effects of the reduced peptide availability and a less effective mediator system in the hypoxic pulmonary vasculature.

Changes in binding sites are not a nonspecific occurrence for all vasoactive peptides in hypoxia. We have demonstrated that binding sites for VIP and ET-1 do not change in hypoxia, even though both peptides have been implicated in the hypoxic response [12, 29]. However, binding of the vasodilator peptide ANP was decreased after 7 days of hypoxia, possibly as a response to the elevated plasma levels of ANP reported in hypoxia [11], where it has been shown to reduce pulmonary arterial pressure [30].

This study, therefore, demonstrates that the control of the pulmonary vasculature is complex and that changes in 
hypoxia include alterations in receptors and secondmessenger systems as an adaptive response to, or causative mechanism of, hypoxic pulmonary hypertension.

\section{References}

1. Cadieux A, Springall DR, Mulderry PK, et al. Occurrence, distribution and ontogeny of CGRP immunoreactivity in the rat lower respiratory tact: effect of capsaicin treatment and surgical denervations. Neuroscience 1986; 19: 605627.

2. Lundberg JM, Franco-Cereceda A, Hua X, Hokfelt T, Fischer JA. Coexistence of substance $\mathrm{P}$ and calcitonin gene-related peptide-like immunoreactivities in sensory nerves in relation to cardiovascular and bronchoconstrictor effects of capsaicin. Eur J Pharmacol 1985; 108: 315-319.

3. Uddman R, Luts A, Sundler F. Occurrence and distribution of calcitonin gene-related peptide in the mammalian respiratory tract and middle ear. Cell Tissue Res 1985; 241: 551-555.

4. McCormack DG, Salonen RO, Barnes PJ. Effect of sensory neuropeptides on canine bronchial and pulmonary vessels in vitro. Life Sci 1989; 45: 2405-2412.

5. Keith IM, Ekman R. Dynamic aspects of regulatory lung peptides in chronic hypoxic pulmonary hypertension. Exp Lung Res 1992; 18: 205-224.

6. Springall DR, Collins G, Barer G, Suggen AJ, Bee D, Polak JM. Increased intracellular levels of calcitonin gene-related peptide-like immunoreactivity in pulmonary endocrine cells of hypoxic rats. J Pathol 1988; 155: 259-267.

7. McBride JT, Springall DR, Winter RJD, Polak JM. Quantitative immunocytochemistry shows calcitonin gene-related peptide-like immunoreactivity in lung neuroendocrine

cells is increased by chronic hypoxia in the rat. Am J Respir Cell Mol Biol 1990; 3: 587-593.

8. Dennis T, Fournier A, St. Pierre S, Quirion R. Structureactivity profile of calcitonin gene-related peptide in peripheral and brain tissues: evidence for receptor multiplicity. J Pharmacol Exp Ther 1989; 251: 718-725.

9. Donoso MV, Fournier A, St Pierre S, Huidobro-Toro JP. Pharmacological characterization of CGRP1 receptor subtype in the vascular system of the rat: studies with CGRP fragments and analogs. Peptides 1990; 11: 885-889.

10. Rakugi H, Tabuchi Y, Nakamaru M, et al. Evidence for endothelin-1 release from resistance vessels of rats in response to hypoxia. Biochem Biophys Res Commun 1990; 169: 973-977.

11. McKenzie JC, Tanaka I, Inagami T, Misono KS, Klein RM. Alterations in atrial and plasma atrial natriuretic factor (ANF) content during development of hypoxia-induced pulmonary hypertension in the rat. Proc Sot Exp Biol Med 1986; 181: 459-463.

12. $\mathrm{Li} \mathrm{X}, \mathrm{Lu} \mathrm{WC}, \mathrm{Zhu} \mathrm{YJ}$. The relation of vasoactive intestinal peptide and acute hypoxia. Chung-Hua-Nei-Ko-Tsa-Chih 1990; 29: 8-10.

13. Adnot S, Raffestin B, Eddahibi S, Braquet P, Chabrier PE. Loss of endothelium-dependent relaxant activity in the pulmonary circulation of rats exposed to chronic hypoxia. $J$ Clin Invest 1991; 87: 155-162.

14. Chaterjee TK, Fisher RA. Multiple affinity forms of the calcitonin gene-related peptide receptor in rat cerebellum. Mol Pharmacol 1991; 39: 798-804.
15. Chaterjee TK, Moy JA, Fisher RA. Characterization and regulation of high affinity forms of the calcitonin generelated peptide receptors in cultured neonatal rat cardiac mycytes. Endocrinology 1991; 128: 2731-2738.

16. Birnbaumer L. Abramowitz J, Brown AM. Receptoreffector coupling by $\mathrm{G}$ proteins. Biochim Biophys Acta 1990; 1031: 163-224.

17. Knock GA, Wharton J, Gaer JAR, Yacoub MH, Taylor KM, Polak JM. Regional distribution and regulation of $\left[{ }^{125} \mathrm{I}\right]$ calcitonin gene-related peptide binding sites in coronary arteries. Eur J Pharmacol 1992; 219: 415-425.

18. Mak JC, Barnes PJ. Autoradiographic localization of calcitonin gene-related peptide (CGRP) binding sites in human and guinea-pig lung. Peptides 1988; 9: 957-963.

19. Liu SF, Crawley DE, Rohde JAL, Evans TW, Barnes PJ. Role of nitric oxide and guanosine 3',5'-cyclic monophosphate in mediating nonadrenergic, noncholinergic relaxation in guinea-pig pulmonary arteries. $\mathrm{Br} \mathrm{J}$ Pharmacol 1992; 107: 861-866.

20. Carville C, Raffestin B, Eddahibi S, Blouquit Y, Adnot S. Loss of endothelium-dependent relaxation in proximal pulmonary arteries from rats exposed to chronic hypoxia: effects of in viva and in vitro supplementation with L-arginine. J Cardiovasc Pharmacol 1993; 22: 889-896.

21. Omar HA, Wolin MS. Endothelium-dependent and independent cGMP mechanisms appear to mediate $\mathrm{O}_{2}$ responses in calf pulmonary resistance arteries. Am J Physiol 1992; 262: L560-565.

22. Kourembanas S, McQuillan LP, Leung GK. Faller DV. Nitric oxide regulates the expression of vasoconstrictors and growth factors by vascular endothelium under both normoxia and hypoxia. J Clin Invest 1993; 92: 99-104.

23. Dinh-Xuan AT. Endothelial modulation of pulmonary vascular tone. Eur Respir J 1992; 5: 757-762.

24. Lauweryns JM, Cokelaere M, Deleersnyder M, Liebens M. Intrapulmonary neuro-epithelial bodies in newborn rabbits: influence of hypoxia, hyperoxia, hypercapnia, nicotine, reserpine, L-DOPA and 5-HT. Cell Tissue Res 1977; 182: 425-440.

25. Lauweryns JM, Cokelaere, Lerut T, Theunynck P. Crosscirculation studies on the influence of hypoxia and hypoxaemia on neuro-epithelial bodies in young rabbits. Cell Tissue Res 1978; 193: 373-386.

26. Roncalli M, Springall DR, Maggioni M, et al. Early changes in the calcitonin gene-related peptide (CGRP) content of pulmonary endocrine cells concomitant with vascular remodelling in the hypoxic rat. Am J Respir Cell Mol Biol 1993; 9: 467-474.

27. Tjen-A-Looi S, Ekman R, Lippton H, Cary J, Keith I. CGRP and somatostatin modulate chronic hypoxic pulmonary hypertension. Am J Physiol 1992; 263: H681690.

28. Kahn CR. Membrane receptors for hormones and neurotransmitters. J Cell Biol 1976; 70: 261-286.

29. Shirakami G, Nakao K, Saito Y, Magaribuchi T, et al. Acute pulmonary alveolar hypoxia increases lung and plasma endothelin-1 levels in conscious rats. Life Sci 1991; 4 969-976.

30. Jin HK, Yang RH, Thornton RM, Chen YF, Jackson R, Oparil S. Atrial natriuretic peptide lowers pulmonary arterial pressure in hypoxia-adapted rats. J Appl Physiol 1988; 65: 1729-1735. 